\title{
Multi drug resistance and $\beta$-lactamase production by Klebsiella pneumoniae
}

\author{
Habeeb Khadri .C ${ }^{1}$, S. Surekha ${ }^{1}$, S. Lakshmi ${ }^{1}$ and G. Narasimha ${ }^{2 *}$ \\ ${ }^{1}$ Department of Microbiology, Government Medical College, Anantapur, A. P. India \\ ${ }^{2}$ Department of Microbiology, National PG College, Nandyal-518502 India.
}

\begin{abstract}
Accepted 22 June, 2007
The extended spectrum $\beta$-lactamase (ESBL) production and multidrug resistant of Klebsiella pneumoniae in children below 5 years of ages are investigated. The $K$. pneumoniae strains isolated from patients suffering from intestinal and extra intestinal infection between the $0-5$ year's ages of children showed resistant to the three antibiotics (ceftazidime, cefotaxime, ceftriaxone), and coexist with non $\beta$-lactam resistance and ESBL production. All the strains were susceptibility to the antibiotic, imipenem. Out off 110 strains only 9 strains produced ESBL. The plasmid responsible for the antibiotic resistance and ESBL production can be transferred to recipient Escherichia coli strain.
\end{abstract}

Key words: Klebsiella pneumoniae, drug resistance, ESBL production.

\section{INTRODUCTION}

Klebsiella pneumoniae is a successful opportunistic pathogen and has been associated with various ailments such as urinary tract infection, septicemia, respiratory tract infection and diarrhea (Podschu and Ullmann, 1998). In 1983, Extended Spectrum $\beta$-Lactamase (ESBL) was found to confer resistance to broad spectrum cephalosporin (Knoth, 1983). Since then the promising and usable spectrum of third generation cephalosporin (3GC) like cefotaxime, ceftriaxone and ceftazidime, in the treatment of multidrug resistant $K$. pneumoniae infection has been limited as resistant strain have been reported (Brun-Buisson et al., 1987; Jarlier et al, 1988; Legakis et al., 1995; Abigail et al., 1995, Hobson et al., 1996, Subha et al., 2003, Abdul Rahaman and Kumar, 2005). The ESBL are mediated by plasmids which encode enzymes that hydrolyze the oxyimino- $\beta$-lactams and monobactams (Aztreonam) but have no effect on cephamycins (cefoxitin and cefotetan), carbapenems (imipenem) and related compounds (Philippon et al., 1989). Most ESBL are mutant forms of sulphyl variable (SHV) enzymes coded by genes located on plasmid that can be easily spread from one organism to another (Sirot, 1995). These enzymes are capable of inactivating a variety of $\beta$-lactam drugs

\footnotetext{
*Corresponding author. E-mail: gnsimha123@rediffmail.com.
}

(Rice, 1999). plasmid that can be easily spread from one organisms to another (Sirot, 1995) these enzymes are capable of inactivating a variety of $\beta$-lactam drugs (Rice, 1999). The ESBL producing organisms often show multidrug resistant as the plasmid carry resistance to antibiotics (Paterson, 1997; Steward, 2001). The increasing antimicrobial resistance among $\mathrm{ESBL}$ producing bacteria makes therapy very difficult and leads to the use of expensive broad spectrum drugs, such as carbanpenems, which are known to be most effective antibiotics against these organisms (Livermore, 1998).

Children of less than five years of age group are very susceptible to intestinal and extra intestinal infections. In this study the ESBL prevalence and antimicrobial susceptibility of $K$. pneumoniae among the children under the 0 - 5 year's ages was investigated.

\section{MATERIALS AND METHODS}

\section{Microorganisms}

The clinical samples including blood, urine, stool and sputum are collected from the patient aged 0 - 5 years, at Government Hospital and Medical College, Anantapur, Andhra Pradesh, India, from the month of April 2005 to March 2006. The pathogenic microorganism $K$. pneumoniae was isolated and identified based on the colony morphology and biochemical reactions (Koneman et al., 1992) and microbial populations were counted. The E. coli ATCC (25922) and 
Table 1. ESBL producing Klebsiella Pneumoniae isolates (110) and in their susceptibility categories by disc diffusion method.

\begin{tabular}{|l|c|c|c|c|}
\hline \multirow{2}{*}{$\begin{array}{c}\text { Susceptibility } \\
\text { category }\end{array}$} & \multicolumn{4}{|c|}{ No. (\%) of ESBL producing isolates with in each category with $\mathbf{3 0} \mathbf{~ m g ~ d i s c ~ o f ~ a n t i b i o t i c}$} \\
\cline { 2 - 5 } & Aztreonam & Cefotaxime & Ceftazidime & Cefoxitin \\
\hline Susceptible & $18(16.3)$ & $17(15.4)$ & $19(17.3)$ & $79(71.8)$ \\
Intermediately resistant & $15(13.6)$ & $54(49)$ & $25(22.7)$ & $8(7.3)$ \\
Resistant & $77(70)$ & $39(35.4)$ & $66(60)$ & $23(20.9)$ \\
\hline
\end{tabular}

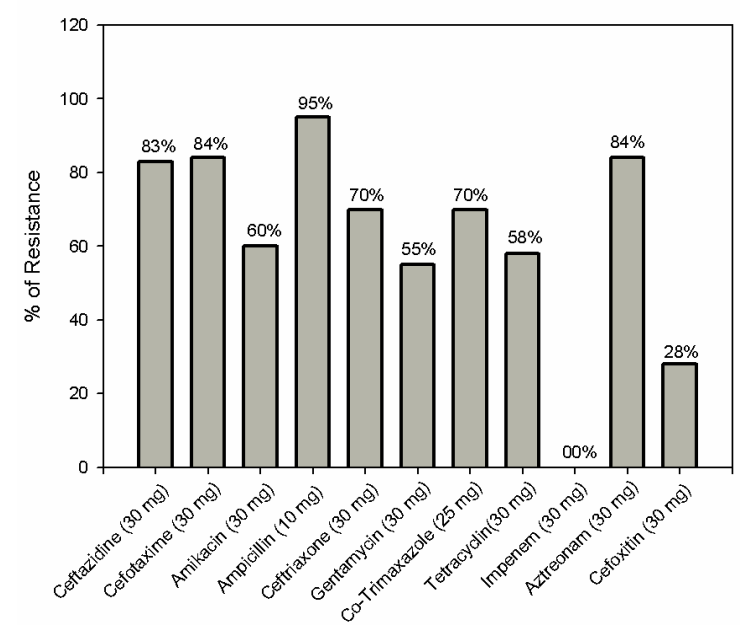

Figure 1. Antibiotic resistance pattern of Klebsiella Pneumoniae isolates.

K. pneumoniae (48188) were obtained from IMTECH, Chandigarh, India.

\section{Double disc approximation test}

ESBL production was carried out by double disc approximation test (Jarlier et al., 1988). The strains were pre-incubated in brain heart infusion broth (BHIB) at $37^{\circ} \mathrm{C}$ and the optimal density of 0.5 . This bacterial suspension was swabbed with sterile cotton on to a Mueller- Hinton agar medium. The antagonistic tests were conducted with antibiotic discs of Amoxicillin/Clavulanic acid $(20 / 10 \mathrm{mg})$ and cefotoxime $(30 \mathrm{mg})$ were placed at a distance of $15 \mathrm{~cm}$ apart from each other and incubated. After incubation the antibiotic activity of Cefotaxime was determined by the formation of inhibition zone.

\section{NCCLS confirmatory test}

The Antibiotic resistance bacterial strain was confirmed by NCCLS (2000) confirmatory test. While performing antibiotic testing ceftazidime $(30 \mathrm{mg})$ and ceftazidime and clavulanic acid $(30 / 10 \mathrm{mg})$ were placed on Mueller Hinton agar media and incubated. After incubation the zone of inhibition was measured by standards method (Bal, 2000).

\section{Transformation test}

The antibiototic resistant and ESBL mediating gene was transferred to recipient $E$. coli $\mathrm{K} 12$ strains. The transconjugates were selected on Macon key agar containing antibiotics nalidixic acid
$(125 \mathrm{mg} / \mathrm{ml})$ and cefotaxime $(0.25 \mu \mathrm{g} / \mathrm{ml})$ and identified biochemically by the method of Koneman et al. (1995).

\section{RESULTS AND DISCUSSION}

The antibiotic resistance pattern and activity of $K$. pneumoniae was detected and shown in the Table 1 and Figure 1. Out off 110 isolates of K. pneumoniae, all are found to be resistant to $3^{\text {rd }}$ generation antibiotics (3GC) and these isolates showed multidrug resistance. 88 $(80 \%)$ of the isolates showed resistance or decreased susceptibility to various $3 G C$ antibiotics (ceftazidime, cefotaxime, ceftriaxone) and coexisted with other antibiotics (Figure 1.) According to Padmini (2004), $90 \%$ of $K$. pneumoniae strains showed resistance to the 3GC antibiotics. Jacoby (1999) also reported that a particular plasmid is responsible for drug resistance and ESBL production. All the isolates were found susceptibility to the antibiotic imipenem. The ESBL production against the antibiotics, ceftazidime, cefotaxime and ceftriaxone was detected in 9 strains of $K$. pneumoniae (6 from urine, 2 from stool and 1 from sputum). The gene responsible for resistance to the $3 G C$ antibiotics and ESBL production was transferred to the recipient $E$. coli strain from 9 ESBL positive isolates. The Transconjugates were selected on Macon key agar containing the antibiotics nalidixic acid $(125 \mathrm{mg} / \mathrm{ml})$ and cefotaxime $(0.25 \mu \mathrm{g} / \mathrm{ml})$ and identified with the biochemical method of Koneman et al. (1995). Similar studies were made Jarlier et al. (1998).

This study has revealed the occurrence of $\beta$-lactamase producing strains of $K$. pneumoniae recovered from children with urinary tract infection, septicemia and respiratory tract infections. ESBL mediating resistance to $3 G C$ was found in $9 \%$ of isolates. The prevalence rate is higher than the reported figure of $K$. pneumoniae in Canada (6.2\%) and United States of America (Jones et al., 1999) and lower in India (Padmini and Applaraju, 2004). The incidence of ESBL producing strains among clinical Klebsiella isolates has steadily increased over the years and account for 6 to $17 \%$ of all nosocomial urinary tract infections. The detection rate of ESBL producing Klebsiella isolate in stool sample ranges from 5 to $38 \%$. While rates in the nasophrynx range from 1 to $6 \%$. In our study, isolates were obtained from stool $(8.3 \%)$, urine $(8.5 \%)$ and respiratory tract infection (16.6\%). In addition to $3 \mathrm{GC}$ antibiotics, the isolates showed resistance to Amikacin (55\%) Tetracycline, (58\%) Co-trimoxozole (70\%) and Gentamicin (55\%). 
The ESBL mediated and resistance gene was transferred to the recipient $E$. coli K 12 strain reported earlier (Jarlier et al., 1998). These plasmids are easily transmitted among bacteria and this accounts for ESBL producing isolates that are resistance to a variety of antibiotics. According to Podschu and Ullmann (1998), the multidrug resistant Klebsiella strain is unfortunately accompanied by a relatively high stability of the plasmids. The present study has shown the incidence of multidrug resistant and ESBL producing Klebsiella isolates among children in Anantapur. Hence routine diagnosis should be carried out to detect ESBL mediated 3GC resistant isolates.

\section{REFERENCES}

Abdul Rahaman KA, Kumar A (2005). Extended spectrum $\beta$-lactamases in urinary isolates of Escherichia coli, Klebsiella pneumoniae and other gram negative bacteria in a hospital. Saudi Med. J. 26(6): 956959.

Abigail S, Mathai E, Jesudason MV, John TJ (1995). Ceftazidime resistance among Klebsiella pneumoniae in South India, Indian J. Med. Res. 102: 53-55.

Bal S (2000). $\beta$-lactamase mediated resistance in hospital acquire urinary tract infection. Hosp. Today 5: 96-101.

Brun-Buisson CB, Legrand P, Phillippon A, Montravers F, Ansquer M, Duval J ( 1987). Transferable enzymatic resistant to third generation cephalosporin during nosocomial out breaks of multi resistant Klebsiella pneumoniae. Lancet. 2: 302-306.

Hobson RP, Mackenzie GM, Gould IM (1996). An out breaks of multiple resistant Klebsiella pneumoniae in the Grampian region of Scotland. J. Hosp. Infect. 33: 249-62.

Jacoby GA, Han P (1996) Detection of extended spectrum $\beta$ lactamases in clinical isolates of Klesiella pneumoniae and E.coli. pp. 908-911.

Jarlier V, Nicolas MH, Fournier G, Phillippon A (1988). Extended broadspectrum $\beta$-lactamases conferring transferable resistance to newer $\beta$ - lactamases agents in enterobacteriaceae; Hospital prevalence and susceptibility pattern. Rev. Infect. Dis. 10: 867-878.

Jacoby GA, Sutton L (1999). Properties of plasmids responsible for production of extended spectrum $\beta$ macadamizes. Antimicron Agents Chemother. pp. 164-169.

Jones RN, Kugler KC, Pfaller MA, Winokur PL (1999). Characterization of pathogens causing Urinary Tract Infection in hospital in North America; Results from the SENTRY, Antimicrobial surveillance program. SENTRY surveillance group. Diagn. Mirobiol. Infect. Dis. 35: 55-63.

Koneman EW, Allen SD, Janda WM, Schreekenberger PC, Winn WC (1992). The enterobacteriaceae in; color atlas and text book of diagnostic microbiology 4th ed, Philadelphia; J.B. Lipincott Co. pp. 105-184.

Legakis NJ, Tzouvelekis LS, Hatzoudis G, Tzelepi E, Gourkou A, Pitt TL (1995) Klebsiella pneumoniae infections in Greek hospitals. Dissemination of plasmids encoding an SHV-5 type $\beta$-lactamase. J. Hosp. Infect. 31: 177-187.
Livermore DM (1998). $\beta$-lactamase mediated resistance and opportunities for its control. J. Antimicrob. Chemother. 41: 25-41.

National Committee for Clinical Laboratory Standards. (2000). Performance standards for antimicrobial disk susceptibility test $7^{\text {th }}$ edition. Approval standard NCCLS, document M2- A7, Vol. 20; Wayne.

Padmini B, Applaraju BS (2004). Extended spectrum $\beta$-lactamases in urinary isolates of E.coli and Klebsiella pneumoniae prevalence and susceptibility pattern in a tertiary care hospital. Indian J. Med. Microbiol. 22: 172-174.

Paterson DL, Motiapatra SK, Vongottberg A (1997). Klebsiella pneumoniae bacterium impact of extended spectrum $\beta$-lactamases (ESBL) production in a global study of 216 patients (abst) in; program and abstract of the 37th inter science conference on antimicrobial agents and chemotherapy Washington, DC; Am. Soc. Microb. pp. 328.

Philippon A, Labia R, Jacoby G (1989). Extended spectrum $\beta$ lactamases, Antimicrob. Agents Chemother. 33: 1131-1136.

Podschu R, Ullmann U (1998). Klebsiella spp. as nosocomial pathogens; Epidemiology, Taxonomy, Typing Methods and Pathogenicity factors. Clin. Microbiol. Rev. 11: 589-603.

Rice LE (1999) Successful interventions for gram negative resistance to extended spectrum $\beta$-lactamases antibiotics. Pharmacotherapy. 19: 120-128.

Subha A, Devi VR, Ananthan S (2003). AmpC $\beta$-lactase producing multi drug resistant strains of klebsiella spp, and Escherichia coli isolated from childrens under five in Chennai, India. Indian J. Med. Res. 117: 13-18.

Sirot D (1995). Extended spectrum plasmid mediated $\beta$-lactamases. J. Antimicrob. Chemother. 36: (suppl) 19-34.

Steward CD, Rasheed JK, Hubert SK, Biddle JW, Raney PM, Anderson G (2001). Characterization of clinical isolates of Klebsiella pneumoniafrom 19 laboratories using the National Committee for Clinical Laboratory Standards, extended spectrum $\beta$-lactamases detection methods. J. Clin. Microbiol. 39: 2864-2872. 